\title{
Provision of smoking care in NSW hospitals: opportunities for further enhancement
}

\author{
Megan A. G. Freund $\mathrm{A,C,D,F}$, \\ Elizabeth M. Campbell ${ }^{\mathrm{A}, \mathrm{C}, \mathrm{D}}$, \\ Christine L. Paul $\mathrm{B}^{\mathrm{B}, \mathrm{C}, \mathrm{D}}$, John H. Wiggers ${ }^{\mathrm{A}, \mathrm{C}, \mathrm{D}}$, \\ Jenny J. Knight ${ }^{\mathrm{A}, \mathrm{C}, \mathrm{D}}$ and Elayne N. Mitchell ${ }^{\mathrm{E}}$ \\ ${ }^{\mathrm{A}}$ Hunter New England Population Health, \\ Hunter New England Area Health Service \\ ${ }^{\mathrm{B}}$ Centre for Health Research and Psycho-oncology (CHeRP), \\ NSW Cancer Council \\ ${ }^{\mathrm{C}}$ The University of Newcastle \\ ${ }^{\mathrm{D}}$ Hunter Medical Research Institute \\ ${ }^{\mathrm{E}}$ Tobacco and Health Branch, NSW Department of Health \\ FCorresponding author.megan.freund@hnehealth.nsw.gov.au
}

\begin{abstract}
The provision of smoking care, including the management of nicotine withdrawal and assistance with a quitting attempt, is identified as an important part of the overall care of hospitalised patients. Levels of smoking care delivery in hospitals have been less than optimal. Increasing this care across multiple facilities and units within NSW Health represents a significant challenge. This article examines levels of smoking care delivery in NSW hospitals, and research evidence and best practice recommendations to inform potential strategies to increase such care. It also reviews statewide initiatives implemented by NSW Health to enhance the delivery of smoking care and suggests further strategies that could facilitate this.
\end{abstract}

A considerable proportion of hospitalised patients are smokers (19-38\%), and of this group, up to two-thirds are nicotine dependent. ${ }^{1-5}$ Smoking is banned in all buildings and grounds of the more than 200 NSW Health hospitals, with few exemptions. ${ }^{6}$ Hence, a significant proportion of the hospital population is likely to require assistance to cope with nicotine withdrawal. ${ }^{7-10}$ Support for quitting is also important, as $25 \%$ of patients report that they are ready to quit smoking and a further $45 \%$ are contemplating quitting. ${ }^{1,9}$ Despite this, the Australian health-care system appears to have regarded smoking as a lifestyle choice, rather than a medical condition to be treated. ${ }^{5}$
Hospital smoking care can be separated into two aspects. First, smoking care can support patients willing to use the hospital contact to commence a permanent quit attempt. ${ }^{10,11}$ Second, for patients unwilling to quit, smoking care can support temporary abstinence during the inpatient stay, provide patients with an opportunity to trial smoking cessation and prompt a future permanent quit attempt. ${ }^{12,13}$ Australia currently lacks a national guideline regarding hospital smoking care. ${ }^{5}$ However, in 2002, in recognition of the need for an evidence-based protocol for the treatment of inpatients who are smokers, the NSW Department of Health released the Guide for the Management of Nicotine Dependent Inpatients (the Guide). ${ }^{11}$ The Guide was sent to Chief Executive Officers of each NSW area health service for distribution to hospitals and training divisions. Although the focus of the Guide was the management of the inpatient stay, it also provided recommendations for smoking-cessation care. The Guide's recommendations were compatible with several international smoking-cessation care guidelines and are summarised in Box 1. ${ }^{12-16}$

\section{Levels of smoking-care provision in NSW public hospitals}

At the time of the Guide's release, a cross-sectional survey of senior managers representing 169 (82\%) NSW public hospitals sought to determine the level of smoking care routinely provided to inpatients. ${ }^{17}$ Approximately twothirds of managers $(68 \%)$ reported most inpatients $(80 \%$ or more) were informed of the smoke-free site policy. Eighty per cent of managers reported that most inpatients had their smoking status recorded in patient medical records. Only 1 to $8 \%$ of respondents reported that most patients were provided nicotine replacement therapy (NRT) or provided discharge-related care (Table 1).

A more robustly evaluated study investigated levels of smoking care provided to 617 nicotine-dependent patients discharged from four regional hospitals 6 to 18 months after the release of the Guide (unpublished data). Patient telephone surveys and audits of medical notes assessed receipt of 11 smoking care practices. The patient survey demonstrated that although the majority $(79 \%)$ of patients were asked about their smoking status, only $47 \%$ were advised they should quit smoking and $8 \%$ were provided with NRT during their stay (Table 2). Discharge-related smoking care was the least provided smoking care element ( 1 to $7 \%$ of patients). The audit of medical notes demonstrated a similar pattern of smoking care delivery. 
Box 1. Care recommended by the Guide for the Management of Nicotine Dependent Inpatients produced by NSW Department of Health

\section{Recommended actions}

1. Identify tobacco users on admission

- Ex-smokers: encourage continued abstinence

- Daily/Occasional smokers: follow steps 2-5

2. Manage inpatient nicotine withdrawal

- Inform patient of the NSW Health Smoke Free Workplace Policy

- Specify treatment contraindications if they leave the ward/facility to smoke

- Discuss options for the management of nicotine dependence:

- abstinence

- abstinence plus nicotine replacement therapy (if not contraindicated)

- smoking off-site/in a designated area

3. Prescribe nicotine replacement therapy

- Arrange prescription of nicotine replacement therapy

- Record:

- nicotine replacement therapy type and dose on medications chart

-'nicotine dependent' in patient notes

4. Monitor patient withdrawal symptoms

- Review nicotine replacement therapy dose/product if patient experiences withdrawal symptoms

\section{Discharge}

- Encourage future quit attempt for patients who plan to resume smoking after discharge

- For patients who do not plan to smoke after discharge:

- Arrange 3 days post discharge nicotine replacement therapy

- Include treatment summary in discharge plan

- Advise patient seek support from GP/pharmacist/ Quitline (Ph: 137848)

Source: NSW Department of Health. Guide for the management of nicotine dependant inpatients. Summary of evidence. NSW Health Department. Sydney 2002

The senior hospital manager survey suggested that levels of smoking-care provision were generally low at the time of the Guide's release, and the later patient survey and notes audit study demonstrated that the dissemination of the Guide had not achieved high levels of smoking care in the hospitals involved. Both studies suggested that a minority of patients were routinely provided smoking care sufficient to assist with a smoking-cessation attempt or to manage nicotine-withdrawal symptoms. This pattern of high levels of smoking status assessment and lower levels of other elements of smoking-care provision is similar to that found in overseas studies. ${ }^{18-24}$ The results suggest that the assessment of smoking status is conducted more as an administrative task, rather than to trigger appropriate care.

\section{Barriers to smoking-care provision}

Poor levels of smoking care may be a result of the unique hospital setting barriers to the provision of such care..$^{25}$ Suggested barriers include: a lack of role delineation regarding who should provide each aspect of smoking care; limited opportunities for follow-up; underutilised referral to quit smoking services; and organisational barriers related to hospital systems not being geared toward preventive care. ${ }^{25}$

The dissemination of the Guide was an important step towards increasing hospital smoking care. However, the Guide's distribution was through relatively passive means. At the time of the Guide's release, no support was provided to area health services to aid its adoption. The clinical practice change literature suggests that passive distribution of guidelines is not likely to be effective, and intensive dissemination methods are required to significantly impact on care provision..$^{26-30}$ This suggestion is supported by the continuing low levels of smoking-care provision in countries that have previously released smoking-cessation care guidelines. ${ }^{18,23,31-36}$

\section{Best practice strategies to increase provision of smoking care}

Guidance regarding the most effective strategies to increase smoking care potentially comes from several sources, including evidence from literature reviews, evidence from well designed individual studies and comments from experts in the field. Currently, there is no review that specifically examines the effectiveness of strategies designed to increase smoking care in hospitals. Reviews of clinical practice change generally have demonstrated that strategies such as educational outreach visits, reminders, interactive educational meetings and multi-faceted interventions are effective. ${ }^{26-30,37}$

Several individual controlled studies have examined the effect of an intervention on levels of hospital smokingcare delivery. ${ }^{21,38-48}$ Most studies employed multiple intervention strategies. ${ }^{21,38,40-43,45,46,48}$ The capacity of this evidence base to guide health care providers is restricted because the majority of studies were: undertaken before the release of smoking-care guidelines; conducted in the USA; addressed single units within a hospital or patient groups with a single diagnosis; and reported on a limited range of smoking care practices (few reported on the provision of NRT and post-discharge cessation assistance). ${ }^{5,21,38-48}$ Such studies reported variable intervention effectiveness, with the majority finding at least one positive outcome.

Since the Guide's release, one published Australian study has addressed intervention effectiveness in increasing hospital smoking care. ${ }^{48} \mathrm{~A}$ randomised controlled trial examined the effect of an intervention on the provision of 
Table 1. Proportion of NSW public hospitals providing smoking care $(n=169)$ reported by a survey of senior hospital managers at the time of the release of the Guide for the Management of Nicotine Dependent Inpatients

\begin{tabular}{|c|c|c|c|c|c|c|c|c|}
\hline \multirow[t]{3}{*}{ Smoking care item provideda } & \multicolumn{8}{|c|}{ Proportion of patients provided care } \\
\hline & \multicolumn{2}{|c|}{$0 \%$} & \multicolumn{2}{|c|}{$5-45 \%$} & \multicolumn{2}{|c|}{$50-75 \%$} & \multicolumn{2}{|c|}{$80-100 \%$} \\
\hline & $n$ & $\%$ & $n$ & $\%$ & $n$ & $\%$ & $n$ & $\%$ \\
\hline Informed Smoke Free Workplace Policy & 18 & 11.7 & 7 & 4.5 & 25 & 16.2 & 104 & 67.5 \\
\hline Smoking status recorded & 3 & 1.9 & 10 & 6.4 & 18 & 11.5 & 125 & 80.1 \\
\hline Nicotine dependence assessed & 49 & 31.4 & 22 & 14.1 & 19 & 12.2 & 67 & 42.9 \\
\hline Smoking management discussed & 37 & 26.1 & 38 & 26.8 & 19 & 13.4 & 48 & 33.8 \\
\hline Nicotine dependence recorded & 58 & 38.9 & 15 & 10.1 & 14 & 9.4 & 62 & 41.6 \\
\hline Prescribed nicotine replacement therapy & 79 & 52.3 & 63 & 41.7 & 8 & 5.3 & 1 & 0.7 \\
\hline Withdrawal symptoms monitored & 88 & 57.5 & 32 & 20.9 & 9 & 5.9 & 24 & 15.7 \\
\hline Asked intent to smoke post-discharge & 91 & 61.5 & 38 & 25.7 & 7 & 4.7 & 12 & 8.1 \\
\hline Provided nicotine replacement therapy on discharge & 123 & 78.8 & 20 & 12.8 & 2 & 1.3 & 11 & 7.1 \\
\hline Smoking treatment in discharge summary & 123 & 79.9 & 22 & 14.3 & 2 & 1.3 & 7 & 4.5 \\
\hline
\end{tabular}

smoking-cessation care in a pre-surgical clinic of a major teaching hospital in NSW (control $n=86$, intervention $n=124$ patients). Intervention strategies included:

- identification of opinion leaders

- establishment of local consensus regarding smokingcare delivery

- computerised support systems to prompt, facilitate and provide elements of cessation care

- tailored self-help material for patients

- staff training

- monitoring and feedback of care provision performance.
That study demonstrated large increases (up to $89 \%$ ) in a range of care elements over the trial's 6 month duration including NRT provision. ${ }^{48}$

Although there is some deficiency in the evidence base, particularly that regarding hospital-wide smoking care across multiple facilities, commentators have provided guidance for how hospital administrators can increase smoking-care delivery. These recommendations include: strong management support; systematic identification and recording of smoking status; tracking systems to ensure smoking-care follow-up; provision of education and

Table 2. Proportion of patients provided with smoking care (11 smoking-care practices) in four regional NSW hospitals. ${ }^{a}$ Results of a survey of nicotine-dependent patients and audits of their medical records following the release of the Guide for the Management of Nicotine Dependent Inpatients

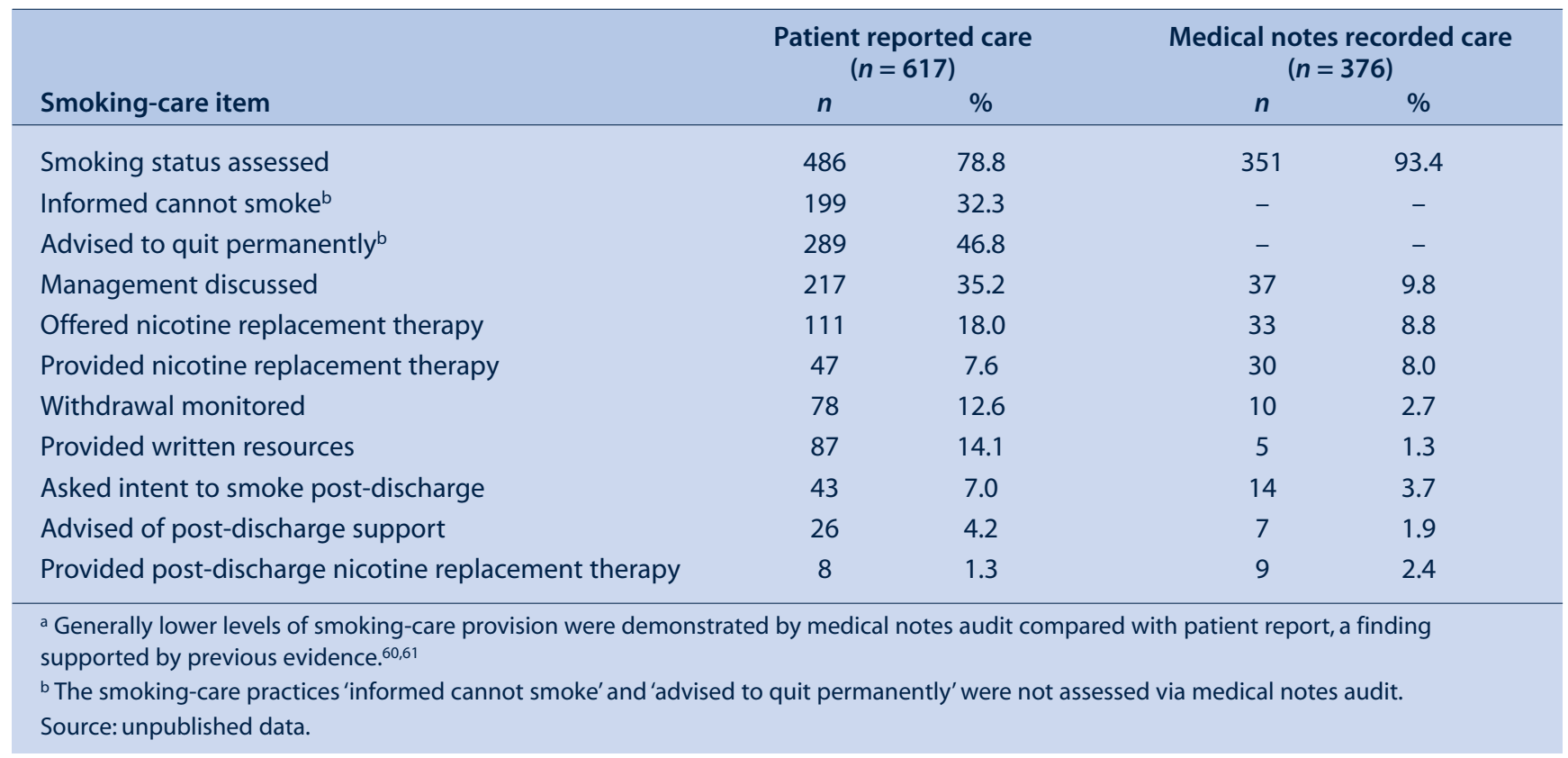


resources to staff; feedback on care delivery performance; identification of health professionals to deliver care; inclusion of nicotine dependence pharmacotherapy on formularies; and smoke-free site compliance. ${ }^{12,13,49}$

\section{NSW Health initiatives to support adoption of smoking care}

Subsequent to the release of the Guide, NSW Health has implemented a range of statewide strategies, in accordance with the available evidence and recommendations, to support hospital smoking care provision. These include:

- Quitline fax referral forms. Clinicians can complete a fax referral form to refer a patient to a free call-back service from the NSW Quitline. ${ }^{50}$

- Accredited smoking-cessation competency training. As part of the national Population Health Training Package, competency standards and learning and assessment materials were developed. A 20-hour pilot training course was delivered via videoconference to more than 300 clinicians at 27 sites in 2007.

- Smoke-free policy. The NSW Health's mandatory 'Progression of the NSW Health Smoke Free Workplace Policy 2005' requires all Area Health Services to progress towards smoke-free campuses.

- Research funding. The NSW Health Promotion Demonstration Grants Scheme funded a study to investigate whether a multi-strategic intervention increased hospital-wide smoking-care provision in two regional hospitals compared with matched controls.

- Clinician and patient smoking-cessation resources. Non-hospital specific resources, such as the guideline, Let's take a moment, quit smoking brief intervention: a guide for all health professionals, and a DVD, Health Smart - Nicotine Replacement Therapy, are available. $^{51}$

- Smoking-cessation forums. Non-hospital specific forums have been convened to assist information sharing, dissemination and advocacy of smoking care (e.g. the Tobacco Control Network (TOBNET) and a smoking-cessation listserve).

The NSW Department of Health has planned several additional activities to further enhance smoking care. These include: a recommendation for systematic collection of hospital patient smoking-status data; encouragement of each area health service to collect data on the provision of smoking-cessation care and smoking-cessation outcomes; statewide standing orders for hospital nurse-initiated NRT provision; and integration of referral to the NSW Health Quitline into hospital discharge plans. ${ }^{8}$

\section{Additional strategies to increase routine provision of smoking care in hospitals}

It is not yet known if significant improvements in smoking-care delivery have occurred in response to the initiatives outlined above. However, based on available evidence and recommendations, several additional strategies may further enhance the delivery of smoking care. These include:

- Supportive systems to prompt and facilitate smoking care. As demonstrated by the Wolfenden et al. study, strategies that more directly address local systems and procedures of care delivery may produce higher levels of smoking care provision. ${ }^{48,52-55}$ The planned initiatives regarding performance monitoring of the recording of smoking status and area health service encouragement to collect data on the provision of smoking care are important. However, to prompt and sustain large scale changes in smoking-care provision, statewide systems including a range of mandated smoking care fields in medical records, linked to automated prompts and Quitline referral, are required. ${ }^{12,54,56-58}$ Existing information technology presents a barrier to the achievement of such a system; however, the planned introduction of electronic medical records may facilitate this in the future. 56,57

- Compliance monitoring and reporting. Currently hospitals are not accountable for the levels of smoking care provided to patients. Increased engagement from hospital leaders may be enhanced if smoking care delivery becomes a reportable requirement for hospital accreditation, similar to US models. ${ }^{57,59}$ This strategy is supported by the National Tobacco Strategy 2004-2009, which calls for the identification and treatment of smokers to be a performance indicator for Australian hospitals. ${ }^{8}$ The routine or regular collection of data describing a range of smoking care practices will also help gauge the impact of implemented initiatives. Compliance monitoring would need to address the potential difficulties in routinely collecting smoking-care data across the diverse hospital medical record systems that currently exist across NSW Health. Recently the NSW Hospital manager survey of smoking-care provision was repeated. Although data are not yet available, the results will provide some insight into the impact of the current initiatives on the delivery of smoking care.

- Smoking-cessation training. It is unlikely that all clinicians will undertake the 20-hour accredited training course made available by the NSW Department of Health or self-educate using existing resources. It is also unlikely that adequate numbers of smoking-cessation counsellors will be provided to each NSW hospital. As it is recommended that all clinicians possess the necessary skills to identify, provide brief advice and refer to ongoing cessation assistance, mandatory routine training similar to infection control training could be considered for all clinical staff. ${ }^{49}$ 


\section{Conclusions}

The initiatives and activities undertaken by NSW Health to date have supported the provision of smoking care to hospitalised patients. However, further initiatives may be required to ensure every patient has the opportunity to be offered this care. Continuing strong leadership and systems-level change at the state level will be required if the maxim 'prevention is everyone's business' is to become a reality with regard to the delivery of hospital smoking care.

\section{References}

1. Baratiny G, Campbell E, Sanson-Fisher R, Cockburn J. Hospital patients receptive to quit smoking advice. Health Promot J Austr 2003; 14(1): 69.

2. Bittoun R, McMahon M, Bryant DH. Smoking in hospitalised patients. Addict Behav 1991; 16(1-2): 79-81. doi:10.1016/0306-4603(91)90043-H

3. Mathers C, Vos T, Stevenson C. Burden of Disease and Injury in Australia. Canberra: Australian Institute of Health and Welfare, 1999.

4. Schofield PE, Hill DJ. How accurate is in-patient smoking status data collected by hospital admissions staff? Aust $N Z J$ Public Health 1999; 23(6): 654-6.

5. Ministerial Council on Drug Strategy. National Tobacco Strategy, 2004-2009: The Strategy. Canberra: Commonwealth of Australia, 2004 Available from: http://www.health.gov.au/ internet/wcms/publishing.nsf/Content/E955EA2B5D178432C A256FD30017A522/\$File/tobccstrat2.pdf. Accessed on 15 May 2007.

6. New South Wales Health Department. Smoke-Free Workplace Policy. Sydney: New South Wales Health Department, 1999.

7. Emmons KM, Goldstein MG. Smokers who are hospitalized: A window of opportunity for cessation interventions. Prev Med 1992; 21: 262-9. doi:10.1016/0091-7435(92)90024-C

8. New South Wales Department of Health. NSW Tobacco Action Plan 2005-2009. Sydney: NSW Department of Health, 2005 Available from: http://www.health.nsw.gov.au/pubs/2005/ pdf/tobacco_ap_vision.pdf. Accessed on 27 April 2007.

9. Rigotti NA, Arnsten JH, McKool KM, Wood-Reid KM, Paternak RC, Singer DE. Smoking by patients in a smoke-free hospital prevalence, predictors, and implications. Prev Med 2000; 31(2): 159-66. doi:10.1006/pmed.2000.0695

10. Zack E. Smoking withdrawal and prolonged hospitalization. Clin J Oncol Nurs 2002; 6(1): 7-11. doi:10.1188/02.CJON.7-11

11. New South Wales Department of Health. Guide for the management of nicotine dependant inpatients. Summary of Evidence. Sydney: NSW Health Department, 2002.

12. Fiore MC, Bailey WC, Cohen SJ, Dorfman SF, Goldstein MG, Gritz ER. Treating tobacco use and dependence: Clinical practice guideline. Rockville, MD, USA: US Department of Health and Human Services, Public Health Service, 2000.

13. West R, McNeill A, Raw M. Smoking cessation guidelines for health professionals: an update. Thorax 2000; 55(12): 987-99. doi:10.1136/thorax.55.12.987

14. Health Promotion Division Ministry of Health. Clinical practice guidelines on treatment of tobacco use and dependence 2003. Kuala Lumpur, Malaysia: Ministry of Health, 2003.
15. Raw M, McNeill A, West R. Smoking cessation guidelines for health professionals. A guide to effective smoking cessation interventions for the health care system. Thorax 1998; 53: S1-18. Suppl 5

16. Wolfenden L, Campbell E, Walsh R, Wiggers J. Smoking cessation interventions for in-patients: a selective review with recommendations for hospital-based health professionals. Drug Alcohol Rev 2003; 22(4): 437-52. doi:10.1080/09595230 310001613967

17. Freund M, Campbell E, Paul C, Sakrouge R, Wiggers J. Smoking care provision in smoke-free hospitals in Australia. Prev Med 2005; 41(1): 151-8. doi:10.1016/j.ypmed.2004. 09.044

18. Ahluwalia JS, Gibson CA, Kenney E, Wallace DD, Resnicow K. Smoking status as a vital sign. J Gen Intern Med 1999; 14: 402-8. doi:10.1046/j.1525-1497.1999.09078.x

19. Barnoya J, Glantz S. Knowledge and use of tobacco among Guatemalan physicians. Cancer Causes Control 2002; 13: 879-81.

20. Bock BC, Becker B, Monteiro R, Partridge R, Fisher S, Spencer J. Physician intervention and patient risk perception among smokers with acute respiratory illness in the emergency department. Prev Med 2001; 32: 175-81. doi:10.1006/ pmed.2000.0799

21. Bolman C, de Vries H, van Breukelen G. Evaluation of a nurse-managed minimal-contact smoking cessation intervention for cardiac inpatients. Health Educ Res 2002; 17(1): 99-116. doi:10.1093/her/17.1.99

22. Nollen NL, Adewale S, Okuyemi KS, Ahluwalia JS, Parakoyi A. Workplace tobacco policies and smoking cessation practices of physicians. J Natl Med Assoc 2004; 96(6): 838-42.

23. Sheahan SL. Documentation of health risks and health promotion counseling by emergency department nurse practitioners and physicians. J Nurs Scholarsh 2000; 32(3): 245-50. doi:10.1111/j.1547-5069.2000.00245.x

24. van Berkel TFM, Boersma H, De Baquert D, Deckers JW, Wood D. Registration and management of smoking behaviour in patients with coronary heart disease. Eur Heart J 1999; 20: 1630-7. doi:10.1053/euhj.1999.1635

25. Orleans CT, Kristeller JL, Gritz ER. Helping hospitalized smokers quit: new directions for treatment and research. J Consult Clin Psychol 1993; 61(5): 778-89. doi:10.1037/ 0022-006X.61.5.778

26. Bero LA, Grilli R, Grimshaw JM. Closing the gap between research and practice: An overview of systematic reviews of interventions to promote the implementation of research findings. $B M J 1998 ; 317(7156)$ : 465-8.

27. Grimshaw J, Eccles M, Thomas R, MacLennan G, Ramsay C, Fraser $\mathrm{C}$ et al. Toward evidence-based quality improvement. Evidence (and its limitations) of the effectiveness of guideline dissemination and implementation strategies 1966-1998. $J$ Gen Intern Med 2006; 21(Suppl 2): S14-20.

28. Grimshaw JM, Shirran L, Thomas R, Mowatt G, Fraser C, Bero L et al. Changing Provider Behavior. Med Care 2001; 39(Supplement 2): II-2-45. doi:10.1097/00005650200108002-00002

29. Grol R, Baker R, Moss F. Quality improvement research: understanding the science of change in health care. Qual Saf Health Care 2002; 11(2): 110-1. doi:10.1136/qhc.11.2.110

30. Solberg LI, Brekke ML, Fazio CJ, Fowles J, Jacobsen DN, Kottke TE et al. Lessons from experienced guideline imple- 
menters: attend to many factors and use multiple strategies. Jt Comm J Qual Improv 2000; 26(4): 171-88.

31. Basnyat PS, Moseley LG, Al-Rawi M, Lewis MH. Medical audit: Smoking: do vascular surgeons practise what they preach? Ann R Coll Surg Engl 2000; 82: 424-7.

32. Bratzler DW, Oehlert WH, Walkingstick K, Murray CK, Shook $\mathrm{C}$, Cardiac CP. Care of acute myocardial infarction in Oklahoma: an update from the Cooperative Cardiovascular Project. J Okla State Med Assoc 2001; 94(10): 443-50.

33. Butler MW, O’Mahoney MJ, Donnelly SC, McDonnell TJ. Managing exacerbations of COPD: Room for improvement. Ir Med J 2004; 97(4): 108-10.

34. Druss BG, Bradford D, Rosenheck RA, Radford MJ, Krumholz HM. Quality of medical care and excess mortality in older patients with mental disorders. Arch Gen Psychiatry 2001; 58(6): 565-72. doi:10.1001/archpsyc.58.6.565

35. Kava T, Taylor J, Gamble E, Partridge MR. The availability of smoking cessation advice from health professionals: A census from one East London District. Respir Med 2000; 94: 983-4. doi:10.1053/rmed.2000.0871

36. Nohria A, Chen Y, Morton DJ, Walsh R, Vlasses PH, Krumholz HM. Congestive Heart Failure: Quality of care for patients hospitalized with heart failure at academic medical centers. Am Heart J 1999; 137(6): 1028-34. doi:10.1016/ S0002-8703(99)70358-3

37. Hulscher MEJL, Wensing M, Van Der Weijend T, Grol R. Interventions to implement prevention in primary care. Cochrane Database of Systematic Reviews 2006; (1): CD000362.

38. Allen B Jr, Pederson LL, Leonard EH. Effectiveness of physicians-in-training counseling for smoking cessation in African Americans. J Natl Med Assoc 1998; 90(10): 597-604.

39. Cooke M, Mattick RP, Walsh RA. Differential uptake of a smoking cessation programme disseminated to doctors and midwives in antenatal clinics. Addiction 2001; 96(3): 495-505. doi:10.1046/j.1360-0443.2001.96349512.x

40. Cooke M, Mattick RP, Walsh RA. Implementation of the 'Fresh Start' smoking cessation programme to 23 antenatal clinics: a randomized controlled trial investigating two methods of dissemination. Drug Alcohol Rev 2001; 20(1): 19-28. doi:10.1080/09595230124432

41. Cooke M, Mattick RP, Campbell E. The dissemination of a smoking cessation program to 23 antenatal clinics: the predictors of initial program adoption by managers. Aust $N Z$ J Public Health 1999; 23(1): 99-103.

42. Hajek P, Taylor Z, Mills P. Brief intervention during hospital admission to help patients to give up smoking after myocardial infarction and bypass surgery: randomised controlled trial. BMJ 2002; 324(7329): 87-9.

43. Mehta RH, Montoye CK, Gallogly M, Baker P, Blount A, Faul J et al. Improving quality of care for acute myocardial infarction. JAMA 2002; 287(10): 1269-76. doi:10.1001/ jama.287.10.1269

44. Rigotti NA, Arnsten JH, McKool KM, Wood-Reid KM, Pasternak RC, Singer DE. Efficacy of a smoking cessation program for hospital patients. Arch Intern Med 1997; 157(22): 2653-8. doi:10.1001/archinte.157.22.2653

45. Schnoll RA, Zhang B, Rue M, Krook JE, Spears WT, Marcus AC et al. Brief physician-initiated quit-smoking strategies for clinical oncology settings: a trial coordinated by the Eastern Cooperative Oncology Group. J Clin Oncol 2003; 21(2): 355-65. doi:10.1200/JCO.2003.04.122
46. Walsh RA, Redman S, Brinsmead MW, Byrne JM, Melmeth A. A smoking cessation program at a public antenatal clinic. Am J Public Health 1997; 87(7): 1201-4.

47. Walsh RA, Redman S, Byrne JM, Melmeth A, Brinsmead MW. Process measures in an antenatal smoking cessation trial: another part of the picture. Health Educ Res 2000; 15(4): 469-83. doi:10.1093/her/15.4.469

48. Wolfenden L, Wiggers J, Knight J, Campbell E, Spigelman A, Kerridge $\mathrm{R}$ et al. Increasing smoking cessation care in a preoperative clinic: a randomized controlled trial. Prev Med 2005; 41(1): 284-90. doi:10.1016/j.ypmed.2004.11.011

49. Miller NH. Translating smoking cessation research findings into clinical practice: the "staying free" program. Nurs Res 2006; 55(Suppl 4): S38-43. doi:10.1097/00006199200607001-00006

50. New South Wales Department of Health. Quitline Referral Forms. Sydney: New South Wales Department of Health, 2007. Available from: http://www.health.nsw.gov.au/publichealth/health-promotion/tobacco/quitting/quitline_alliance.pdf. Accessed 1 June 2007.

51. New South Wales Department of Health. Cessation Resources. Sydney: New South Wales Department of Health, 2007. Available from: http://www.health.nsw.gov.au/publichealth/health-promotion/tobacco/resources/cessation.html. Accessed 1 June 2007.

52. Curry SJ. Organizational interventions to encourage guideline implementation. Chest 2000; 118(2): 40S-6S. doi:10.1378/chest.118.2_suppl.40S

53. Orleans CT, Woolf SH, Rothemich SF, Marks JS, Isham GJ. The top priority: building a better system for tobacco-cessation counseling. Am J Prev Med 2006; 31(1): 103-6. doi:10.1016/ j.amepre.2006.03.015

54. Goldstein MG. Missed opportunities to assist hospitalized smokers. Am J Prev Med 1999; 17(4): 317-8. doi:10.1016/ S0749-3797(99)00096-3

55. Lancaster T, Silagy C, Fowler G. Training health professionals in smoking cessation (Review). Cochrane Database of Systematic Reviews 2000; (3): CD000214. doi:10.1002/ 14651858.CD000214

56. Conroy MB, Majchrzak NE, Silverman CB, Chang Y, Regan S, Schneider LI et al. Measuring provider adherence to tobacco treatment guidelines: a comparison of electronic medical record review, patient survey, and provider survey. Nicotine Tob Res 2005; 7(Suppl 1): S35-43. doi:10.1080/14622200 500078089

57. Keller PA, Fiore MC, Curry SJ, Orleans CT. Systems change to improve health and health care: lessons from addressing tobacco in managed care. Nicotine Tob Res 2005; 7(Suppl 1): S5-8. doi:10.1080/14622200500077966

58. Lichtenstein E. Behavioral research contributions and needs in cancer prevention and control: tobacco use prevention and cessation. Prev Med 1997; 26(5 Pt 2): 557-63. doi:10.1006/ pmed.1997.0210

59. Orleans CT, Abrams DB, Gruman JC. Will healthcare take tobacco addiction seriously? Using policy to drive practice. Medscape General Medicine 2001; 3(2): 15.

60. Solberg LI. Practical implications of recall bias. Tob Control 1996; 5(2): 95-6.

61. Ward JE, Sanson-Fisher RW. Accuracy of patient recall of opportunistic smoking cessation advice in general practice. Tob Control 1996; 5(1): 110-3. 